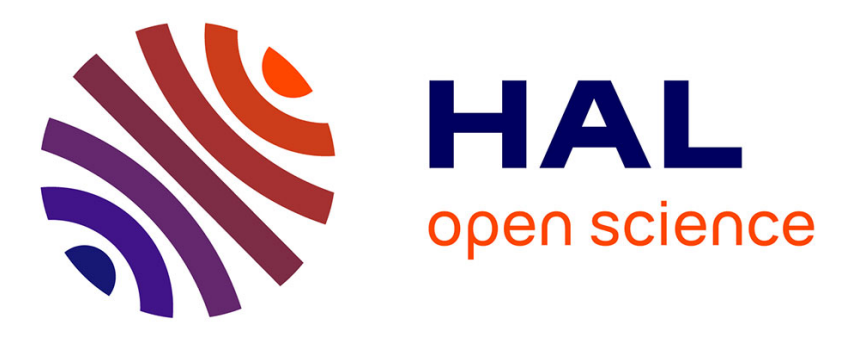

\title{
Dissolution dynamic nuclear polarization of deuterated molecules enhanced by cross-polarization
}

\author{
Dennis Kurzbach, Emmanuelle M.M Weber, Aditya Jhajharia, Samuel F. \\ Cousin, Aude Sadet, Sina Marhabaie, Estel Canet, Nicolas Birlirakis, Jonas \\ Milani, Sami Jannin, et al.
}

\section{To cite this version:}

Dennis Kurzbach, Emmanuelle M.M Weber, Aditya Jhajharia, Samuel F. Cousin, Aude Sadet, et al. Dissolution dynamic nuclear polarization of deuterated molecules enhanced by cross-polarization. Journal of Chemical Physics, 2016, 145 (19), pp.194203. 10.1063/1.4967402 . hal-01405870

\section{HAL Id: hal-01405870 \\ https://hal.science/hal-01405870}

Submitted on 21 Dec 2016

HAL is a multi-disciplinary open access archive for the deposit and dissemination of scientific research documents, whether they are published or not. The documents may come from teaching and research institutions in France or abroad, or from public or private research centers.
L'archive ouverte pluridisciplinaire HAL, est destinée au dépôt et à la diffusion de documents scientifiques de niveau recherche, publiés ou non, émanant des établissements d'enseignement et de recherche français ou étrangers, des laboratoires publics ou privés. 


\section{Dissolution dynamic nuclear polarization of deuterated molecules enhanced by cross-polarization}

Dennis Kurzbach, Emmanuelle M. M. Weber, Aditya Jhajharia, Samuel F. Cousin, Aude Sadet, Sina Marhabaie, Estel Canet, Nicolas Birlirakis, Jonas Milani, Sami Jannin, Dmitry Eshchenko, Alia Hassan, Roberto Melzi, Stephan Luetolf, Marco Sacher, Marc Rossire, James Kempf, Joost A. B. Lohman, Matthias Weller, Geoffrey Bodenhausen, and Daniel Abergel

Citation: J. Chem. Phys. 145, 194203 (2016); doi: 10.1063/1.4967402

View online: http://dx.doi.org/10.1063/1.4967402

View Table of Contents: http://aip.scitation.org/toc/jcp/145/19

Published by the American Institute of Physics 


\title{
Dissolution dynamic nuclear polarization of deuterated molecules enhanced by cross-polarization
}

\author{
Dennis Kurzbach, ${ }^{1,2, a)}$ Emmanuelle M. M. Weber, ${ }^{1,2}$ Aditya Jhajharia, ${ }^{1,2}$ Samuel F. Cousin, ${ }^{1,2}$ \\ Aude Sadet, ${ }^{1,2}$ Sina Marhabaie,,$^{1,2}$ Estel Canet, ${ }^{1,2,3}$ Nicolas Birlirakis, ${ }^{1,2}$ Jonas Milani, ${ }^{3}$ \\ Sami Jannin, ${ }^{3,4,5}$ Dmitry Eshchenko, ${ }^{5}$ Alia Hassan, ${ }^{5}$ Roberto Melzi, ${ }^{6}$ Stephan Luetolf, ${ }^{5}$ \\ Marco Sacher, ${ }^{5}$ Marc Rossire, ${ }^{5}$ James Kempf, ${ }^{7}$ Joost A. B. Lohman, ${ }^{8}$ Matthias Weller, ${ }^{5}$ \\ Geoffrey Bodenhausen, ${ }^{1,2,3}$ and Daniel Abergel ${ }^{1,2}$ \\ ${ }^{1}$ Département de Chimie, Ecole Normale Supérieure, PSL Research University, UPMC Univ Paris 06, CNRS, \\ Laboratoire des Biomolecules (LBM), 24 rue Lhomond, 75005 Paris, France \\ ${ }^{2}$ Sorbonne Universités, UPMC Univ Paris 06, Ecole Normale Supérieure, CNRS, \\ Laboratoire des Biomolecules (LBM), Paris, France \\ ${ }^{3}$ Institut des Sciences et Ingénierie Chimiques, Ecole Polytechnique Fédérale de Lausanne (EPFL), Batochime, \\ CH-1015 Lausanne, Switzerland \\ ${ }^{4}$ Univ Lyon, CNRS, Université Claude Bernard Lyon 1, ENS de Lyon, Institut des Sciences Analytiques, \\ UMR 5280, 5 Rue de la Doua, 69100 Villeurbanne, France \\ ${ }^{5}$ Bruker BioSpin, Industriestrasse 26, 8117 Fällanden, Switzerland \\ ${ }^{6}$ Bruker BioSpin, Viale V. Lancetti 43, 20158 Milano, Italy \\ ${ }^{7}$ Bruker BioSpin, 15 Fortune Drive, Billerica, Maryland 01821, USA \\ ${ }^{8}$ Bruker UK Limited, Banner Lane, Coventry CV4 9GH, United Kingdom
}

(Received 1 July 2016; accepted 17 October 2016; published online 18 November 2016)

\begin{abstract}
We present novel means to hyperpolarize deuterium nuclei in ${ }^{13} \mathrm{CD}_{2}$ groups at cryogenic temperatures. The method is based on cross-polarization from ${ }^{1} \mathrm{H}$ to ${ }^{13} \mathrm{C}$ and does not require any radio-frequency fields applied to the deuterium nuclei. After rapid dissolution, a new class of longlived spin states can be detected indirectly by ${ }^{13} \mathrm{C}$ NMR in solution. These long-lived states result from a sextet-triplet imbalance (STI) that involves the two equivalent deuterons with spin $I=1$. An STI has similar properties as a triplet-singlet imbalance that can occur in systems with two equivalent $I=1 / 2$ spins. Although the lifetimes $T_{\mathrm{STI}}$ are shorter than $T_{1}\left(\mathrm{C}_{\mathrm{z}}\right)$, they can exceed the life-time $T_{1}\left(\mathrm{D}_{\mathrm{z}}\right)$ of deuterium Zeeman magnetization by a factor of more than 20. Published by AIP Publishing. [http://dx.doi.org/10.1063/1.4967402]
\end{abstract}

\section{INTRODUCTION}

Recent years have witnessed the rapid development of both theoretical and experimental aspects of dissolution dynamic nuclear polarization (D-DNP). ${ }^{1}$ This method allows one to achieve dramatic signal enhancements in liquid-state nuclear magnetic resonance (NMR) experiments. ${ }^{2}$ D-DNP offers a wealth of novel possibilities for clinical applications like magnetic resonance imaging (MRI), ${ }^{3}$ drug screening, ${ }^{4-7}$ and NMR of biomolecules. ${ }^{8-10}$ To extend the lifetimes of hyperpolarization, D-DNP has been combined with long-lived states. ${ }^{1-13}$ Apart from a few exotic nuclei, ${ }^{14-16} \mathrm{D}$-DNP has so far mostly focused on ${ }^{1} \mathrm{H}$ and ${ }^{13} \mathrm{C}$. Here we propose to extend this methodology by adding deuterium to the list of accessible nuclei, opening new avenues for D-DNP, such as the study of the dynamics of deuterated molecules and improved sensitivity of deuterium NMR.

The concept of D-DNP ${ }^{1}$ is based on the hyperpolarization of nuclear spin states at low temperatures (typically, the spin temperatures are near $10 \mathrm{mK}$ for sample temperatures between 1.2 and $4.2 \mathrm{~K}$ ) in high static magnetic fields (6.7 T in our laboratory). Molecules of interest are usually dissolved in a glass-forming solution and doped with polarizing agents

${ }^{\text {a) Electronic address: kurzbach@ens.fr }}$ containing unpaired electrons. The electron spin transitions of the polarizing agents are saturated with microwaves ( $\mu$ wave) which boost the polarization of nearby nuclear spins. Our preferred approach uses nitroxide radicals like TEMPOL (4-hydroxy-2,2,6,6-tetramethylpiperidine-1-oxyl) that have broad electron paramagnetic resonance (EPR) lines. DNP leads to an efficient enhancement of the nuclear polarization of protons via a combination of the so-called solid effect and thermal mixing. The enhanced ${ }^{1} \mathrm{H}$ polarization can then be transferred to ${ }^{13} \mathrm{C}$ or other nuclei $S$ with gyromagnetic ratios $\gamma_{S}$ via cross polarization $(\mathrm{CP}){ }^{2,17}$ Finally, the frozen hyperpolarized sample is rapidly dissolved with superheated solvents such as $\mathrm{D}_{2} \mathrm{O}$ and transferred to a conventional NMR or MRI apparatus for detection in solution. Signal enhancements by factors up to 50000 can be achieved for ${ }^{13} \mathrm{C}^{2,18}$

At first sight, deuterium does not seem an attractive nucleus for D-DNP, since its polarization $P(\mathrm{D})=P\left({ }^{2} \mathrm{H}\right)$ is proportional to the longitudinal magnetization which we shall refer to as $D_{z}$. It usually decays rapidly with a characteristic longitudinal relaxation time $T_{1}\left(\mathrm{D}_{\mathrm{z}}\right)$ that is on the order of $1 \mathrm{~s}$ under our experimental conditions, i.e., for small molecules with correlation times in the low picosecond range at room temperature in high magnetic fields. ${ }^{19}$ Since the transfer of the hyperpolarized substances after dissolution to an NMR or MRI system typically requires 4-10 s (unless it is accelerated 
by high pressure ${ }^{20}$ ), most $D_{z}$ magnetization will be lost by the time the sample arrives in the NMR or MRI apparatus because of rapid quadrupolar relaxation.

To circumvent this problem, we here propose a means to hyperpolarize long-lived states involving pairs of deuterium nuclei that have scalar couplings to a ${ }^{13} \mathrm{C}$ nucleus. This approach is based on CP to polarize the nuclei of interest and subsequent exploitation of long-lived spin states.

\section{THEORY}

The sample that we investigated consists of perdeuterated ethanol- $\mathrm{d}_{6}$, with ${ }^{13} \mathrm{C}$ in $1.1 \%$ natural abundance (the observed ${ }^{13} \mathrm{C}$ spin system is therefore highly dilute), $\mathrm{H}_{2} \mathrm{O}$ to provide a reservoir of protons to allow "remote" $\mathrm{CP}$ from the protons of the solvent to the ${ }^{13} \mathrm{C}$ nuclei in the deuterated molecules, glycerol as glass-forming agent, and TEMPOL as polarizing agent. Here, we focus on the spin dynamics of the ${ }^{13} \mathrm{CD}_{2}$ group of ethanol- $\mathrm{d}_{6}$. The ${ }^{13} \mathrm{CD}_{3}$ group will be discussed elsewhere. ${ }^{21,22}$

\section{Cross polarization of systems with heteronuclear couplings}

The CP sequence in Fig. 1(a) uses adiabatic sweeps to convert part of the ${ }^{1} \mathrm{H}$ magnetization of water to the ${ }^{13} \mathrm{C}$ nuclei of ethanol- $\mathrm{d}_{6}$ through long-range intermolecular dipolar couplings by fulfilling the Hartmann-Hahn condition. ${ }^{17}$ The objective of CP is to convert the transverse magnetization $I_{\mathrm{x}}$ into $S_{\mathrm{x}}$ in the rotating frame via a spin lock of duration $\tau_{\mathrm{SL}}$ with rf amplitudes $\gamma B_{1}{ }^{I}$ and $\gamma B_{1}{ }^{S}$. In the present case, where $I={ }^{1} \mathrm{H}$ and $S={ }^{13} \mathrm{C}$, we use the notation $I_{\mathrm{x}}=\mathrm{H}_{\mathrm{x}}$ and $S_{\mathrm{x}}=\mathrm{C}_{\mathrm{x}}$. If the CP spin locking field is sandwiched between two $\pi / 2$ pulses, one can transform $\mathrm{H}_{\mathrm{z}}$ into $\mathrm{C}_{\mathrm{z}}$ in the laboratory frame. ${ }^{2}$ In practice, the conversion from $\mathrm{H}_{\mathrm{x}}$ to $\mathrm{C}_{\mathrm{x}}$ is not ideal because the rf field amplitudes are not strong enough to cover the full breadth of the spectra at $1.2 \mathrm{~K}$. In $\mathrm{CD}_{2}$ groups, scalar and dipole-dipole couplings between D and ${ }^{13} \mathrm{C}$, denoted $J_{C D}$ and $D_{C D}$, affect the outcome of cross-polarization from ${ }^{1} \mathrm{H}$ to ${ }^{13} \mathrm{C}$. The former are isotropic and on the order of $20 \mathrm{~Hz}$, while the latter depend on the orientation of the $\mathrm{C}-\mathrm{D}$ bond with respect to the static field and are on the order of $-3.6<D_{C D}<+1.8 \mathrm{kHz}$. In the spirit of the pioneering work on dipolar oscillations by Müller et al., ${ }^{23}$ we shall describe the spin subsystem comprising three reasonably isolated spins $-{ }^{13} \mathrm{C}, \mathrm{D}$, and $\mathrm{D}^{\prime}-$ in terms of a density operator that evolves coherently under the Hamiltonian, using products of angular momentum operators that are widely used to describe NMR in liquids, rather than spin thermodynamics. During CP, the couplings $D_{C D}$ may lead to the appearance of antiphase and doubly antiphase coherences of the form $3^{-1 / 2} \mathrm{C}_{\mathrm{x}} \mathrm{D}_{\mathrm{z}}, 3^{-1 / 2} \mathrm{C}_{\mathrm{x}} \mathrm{D}_{\mathrm{z}}^{\prime}$, and $2^{-1 / 2} \mathrm{C}_{\mathrm{x}} \mathrm{D}_{\mathrm{z}} \mathrm{D}_{\mathrm{z}}^{\prime}$ which after the final $-\pi / 2$ "flip-back" pulse lead to longitudinal two- and three-spin order terms $3^{-1 / 2} \mathrm{C}_{\mathrm{z}} \mathrm{D}_{\mathrm{z}}, 3^{-1 / 2} \mathrm{C}_{\mathrm{z}} \mathrm{D}_{\mathrm{z}}^{\prime}$, and $2^{-1 / 2} \mathrm{C}_{\mathrm{z}} \mathrm{D}_{\mathrm{z}} \mathrm{D}_{\mathrm{z}}^{\prime} \cdot{ }^{24}$ Some of these terms project onto states with long lifetimes, as will be shown below.The norm of an operator $A$ is defined as usual as the square root of its scalar product with itself, $\sqrt{\operatorname{Tr}\left\{A^{\dagger} \cdot A\right\}}$. All product operators of the three isolated spins ${ }^{13} \mathrm{C}, \mathrm{D}$, and $\mathrm{D}^{\prime}$ can be represented by 18 $\times 18$ dimensional matrices.

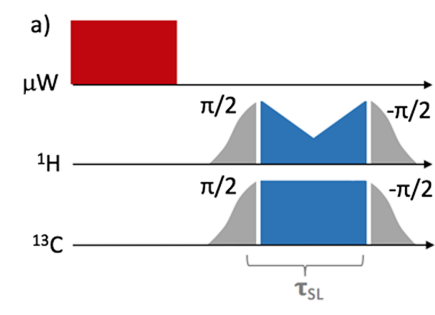

b)
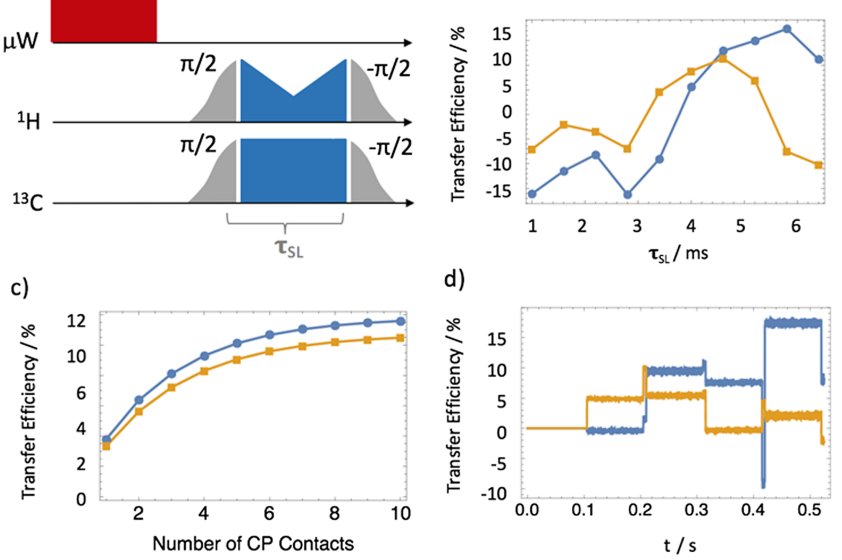

d)

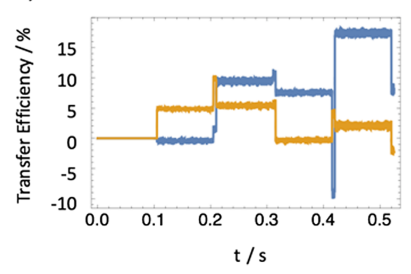

FIG. 1. (a) Cross polarization sequence designed to polarize ${ }^{13} \mathrm{C}$ nuclei starting from ${ }^{1} \mathrm{H}$ nuclei. If the rf field $\gamma B_{1}^{\mathrm{C}} /(2 \pi)$ is not strong enough to decouple the dipolar couplings $D_{C D}$ between the ${ }^{13} \mathrm{C}$ nucleus and the deuterons, crosspolarization leads to three terms $3^{-1 / 2} \mathrm{C}_{\mathrm{z}} \mathrm{D}_{\mathrm{z}}, 3^{-1 / 2} \mathrm{C}_{\mathrm{z}} \mathrm{D}_{\mathrm{z}}^{\prime}$, and $2^{-1 / 2} \mathrm{C}_{\mathrm{Z}} \mathrm{D}_{\mathrm{Z}} \mathrm{D}_{\mathrm{z}}^{\prime}$ after the spin-locking interval $\tau_{\mathrm{SL}}$. The gray shapes indicate $90^{\circ}$ half-passage adiabatic chirp pulses used to flip the ${ }^{1} \mathrm{H}$ and ${ }^{13} \mathrm{C}$ magnetizations from the $z$ to the $x$ axes of the doubly rotating frame and back. The proton spin-lock amplitude $\gamma B_{1}\left({ }^{1} \mathrm{H}\right)$ is ramped (over $50 \%$ of the initial intensity) while the carbon spin-lock amplitude $\gamma B_{1}\left({ }^{13} \mathrm{C}\right)$ remains constant (indicated by the blue shapes). The frequency-modulated $\mu \mathrm{W}$ irradiation (red rectangle) is interrupted ("gated") $1 \mathrm{~s}$ before the CP sequence to allow the electron polarization to return to its Boltzmann equilibrium (the time axis is not true to scale; for details see experimental section on D-DNP). (b) Build-up of the $3^{-1 / 2} C_{z} D_{z}$ (yellow) and $2^{-1 / 2} \mathrm{C}_{\mathrm{Z}} \mathrm{D}_{\mathrm{Z}} \mathrm{D}^{\prime}{ }_{\mathrm{z}}$ (blue) terms as a function of the duration $\tau_{\mathrm{SL}}$ of the spin-locking interval for an $r f$ amplitude $\gamma B_{1}\left({ }^{13} \mathrm{C}\right) /(2 \pi)=50 \mathrm{kHz}$, obtained by numerical simulations using SpinDynamica with averaging over 200 orientations of ethanol- $\mathrm{d}_{6}$ molecules in the glassy state. The vertical scale corresponds to the fraction $(\%)$ of conversion of the longitudinal operators $\mathrm{C}_{\mathrm{z}}$ into terms $3^{-1 / 2} \mathrm{C}_{\mathrm{z}} \mathrm{D}_{\mathrm{z}}, 3^{-1 / 2} \mathrm{C}_{\mathrm{z}} \mathrm{D}^{\prime}{ }_{\mathrm{z}}$, and $2^{-1 / 2} \mathrm{C}_{\mathrm{z}} \mathrm{D}_{\mathrm{z}} \mathrm{D}^{\prime}{ }_{\mathrm{z}}$ during a single $\mathrm{CP}$ contact. (c) Simulated build-up of the $3^{-1 / 2} \mathrm{C}_{\mathrm{Z}} \mathrm{D}_{\mathrm{z}}$ (yellow) and $2^{-1 / 2} \mathrm{C}_{\mathrm{Z}} \mathrm{D}_{\mathrm{Z}} \mathrm{D}^{\prime}{ }_{\mathrm{Z}}$ (blue) terms as a function of the number of $\mathrm{CP}$ contacts for $\tau_{\mathrm{SL}}=1 \mathrm{~ms}$ and $\gamma B_{1}\left({ }^{13} \mathrm{C}\right) /(2 \pi)=50 \mathrm{kHz}$. The vertical scale is relative to $100 \%{ }^{13} \mathrm{C}$ polarization present before the first $\mathrm{CP}$ contact. (d) Time evolution of $3^{-1 / 2} \mathrm{C}_{\mathrm{Z}} \mathrm{D}_{\mathrm{Z}}$ (yellow) and $2^{-1 / 2} \mathrm{C}_{\mathrm{Z}} \mathrm{D}_{\mathrm{Z}} \mathrm{D}^{\prime}{ }_{\mathrm{Z}}$ (blue) terms for $\tau_{\mathrm{SL}}=5 \mathrm{~ms}$ and $\gamma B_{1}\left({ }^{13} \mathrm{C}\right) /(2 \pi)$ $=10 \mathrm{kHz}$ for a constant ${ }^{13} \mathrm{C}$ polarization (in the absence of $\mathrm{cw}$ - $\mu$ wave irradiation) due to repetitions of the carbon pulses shown in (a).

The extent of the transformation of hyperpolarized $\mathrm{H}_{z}$ magnetization into the terms $3^{-1 / 2} \mathrm{C}_{\mathrm{z}} \mathrm{D}_{\mathrm{z}}, 3^{-1 / 2} \mathrm{C}_{\mathrm{z}} \mathrm{D}_{\mathrm{z}}^{\prime}$, and $2^{-1 / 2} \mathrm{C}_{\mathrm{Z}} \mathrm{D}_{\mathrm{Z}} \mathrm{D}_{\mathrm{Z}}^{\prime}$ varies with the duration $\tau_{\mathrm{SL}}$ and the amplitudes $\gamma B_{1}\left({ }^{1} \mathrm{H}\right)$ and $\gamma B_{1}\left({ }^{13} \mathrm{C}\right)$ of the spin-locking fields. In the case at hand, $D_{C D}=-1.8 \times\left[3 \cos ^{2} \theta-1\right] \mathrm{kHz}, J_{C D}=18.5 \mathrm{~Hz}$, $\gamma B_{1}{ }^{\mathrm{C}} /(2 \pi)=\gamma B_{1}{ }^{\mathrm{H}} /(2 \pi)=10-50 \mathrm{kHz}$, and $B_{0}=6.7 \mathrm{~T}$. The value of $D_{C D}$ used in the simulations is based on the geometry of the spin system.

For the simulations of Fig. 1(b), it was assumed that a certain amount of spin order terms, $2^{1 / 2} / 3 \mathrm{C}_{\mathrm{z}}, 3^{-1 / 2} / 2 \mathrm{D}_{\mathrm{z}}$, and $3^{-1 / 2} / 2 D_{\mathrm{z}}{ }^{\prime}$, are present at the beginning of the crosspolarization period. ${ }^{2}$ Subsequently, we computed the entire ${ }^{13} \mathrm{C}$ spin locking sequence, and incorporated off-resonance effects and all intramolecular dipolar and scalar interactions of a $\mathrm{CD}_{2}$ system in an isotropic glass. The powder average over 200 orientations was computed to account for the angular dependence of the dipolar interaction. According to our simulations, approximately $15 \%$ of the initial carbon polarization is transformed after a single $\mathrm{CP}$ contact into each of the $3^{-1 / 2} \mathrm{C}_{\mathrm{z}} \mathrm{D}_{\mathrm{z}}, 3^{-1 / 2} \mathrm{C}_{\mathrm{z}} \mathrm{D}_{\mathrm{z}}^{\prime}$, and $2^{-1 / 2} \mathrm{C}_{\mathrm{z}} \mathrm{D}_{\mathrm{z}} \mathrm{D}^{\prime}{ }_{\mathrm{z}}$ terms. After a train of several CP contacts, a significant fraction (about 50\%-60\% as judged from our simulations, vide infra) of the total carbon 
polarization occurs in the form of such multi-spin terms (see Fig. 1(c)). In comparison to direct hyperpolarization of deuterium (using only microwave irradiation without $\mathrm{CP})^{1}$ the $3^{-1 / 2} \mathrm{C}_{\mathrm{z}} \mathrm{D}_{\mathrm{z}}$ and $2^{-1 / 2} \mathrm{C}_{\mathrm{z}} \mathrm{D}_{\mathrm{z}} \mathrm{D}^{\prime}{ }_{\mathrm{z}}$ terms are enhanced by an order of magnitude without applying any radio-frequency field to the deuterium nuclei. In our experiments, we applied a train of $15 \mathrm{CP}$ contacts of duration $\tau_{\mathrm{SL}}=5 \mathrm{~ms}$ at intervals $\tau=120 \mathrm{~s}$ with an rf amplitude $\gamma \mathrm{B}_{1}^{\mathrm{C}} /(2 \pi)=50 \mathrm{kHz}$. Under these conditions the spin order that can contribute to ${ }^{13} \mathrm{C}$ signals is, apart from $2^{1 / 2} / 3 \mathrm{C}_{\mathrm{z}}$, mostly found in the operator terms $3^{-1 / 2} \mathrm{C}_{\mathrm{z}} \mathrm{D}_{\mathrm{z}}$, $3^{-1 / 2} \mathrm{C}_{\mathrm{z}} \mathrm{D}^{\prime}{ }_{\mathrm{z}}$, and $2^{-1 / 2} \mathrm{C}_{\mathrm{Z}} \mathrm{D}_{\mathrm{z}} \mathrm{D}^{\prime}{ }_{\mathrm{z}}$. According to our simulations, about $30 \%$ of the initial carbon polarization can be transferred into $3^{-1 / 2} \mathrm{C}_{\mathrm{z}} \mathrm{D}_{\mathrm{z}}, 3^{-1 / 2} \mathrm{C}_{\mathrm{z}} \mathrm{D}^{\prime}{ }_{\mathrm{z}}$, and $2^{-1 / 2} \mathrm{C}_{\mathrm{z}} \mathrm{D}_{\mathrm{z}} \mathrm{D}^{\prime}{ }_{\mathrm{z}}$ by a single $\mathrm{CP}$ contact (cf. Fig. 1(b)). A train of consecutive CPs can augment this share to $50 \%-60 \%$ (Fig. 1(c)). However, it has to be taken into account that these simulations are oversimplifying the spin system. Furthermore, once a steady ${ }^{13} \mathrm{C}$ polarization is reached, the $3^{-1 / 2} \mathrm{C}_{\mathrm{z}} \mathrm{D}_{\mathrm{z}}, 3^{-1 / 2} \mathrm{C}_{\mathrm{z}} \mathrm{D}_{\mathrm{z}}^{\prime}$, and $2^{-1 / 2} \mathrm{C}_{\mathrm{z}} \mathrm{D}_{\mathrm{z}} \mathrm{D}_{\mathrm{z}}^{\prime}$ terms will further be transformed by further CP contacts (Fig. 1(d)) in an unpredictable fashion as the strong dipolar coupling between carbon and deuterium leads to rapid oscillations between inphase and anti-phase terms during the spin lock. A coherent manipulation to populate the multi-spin terms is thus complicated in the absence of a deuterium coil. Such a coil will be constructed in our laboratory in the near future. Experimentally, we found that 15 contacts yield a significant contribution of multi-spin terms to the overall polarization. To the best of our knowledge, such side-effects of CP have never been described so far.

\section{Observation of long-lived states after dissolution}

After the train of CP contacts, the hyperpolarized sample is dissolved with $5 \mathrm{ml} \mathrm{D}_{2} \mathrm{O}$ heated to $180{ }^{\circ} \mathrm{C}$ at 10.5 bars. Subsequent transfer in $10 \mathrm{~s}$ to a conventional $400 \mathrm{MHz}$ NMR spectrometer through a $0.9 \mathrm{~T}$ magnetic tunnel ${ }^{25}$ is followed by ${ }^{13} \mathrm{C}$ detection of the hyperpolarized sample in solution at ambient temperatures.

During and after dissolution, several processes take place. The most important one for the interpretation of our observations is the projection of the term $2^{-1 / 2} \mathrm{C}_{\mathrm{Z}} \mathrm{D}_{\mathrm{Z}} \mathrm{D}_{\mathrm{Z}}^{\prime}$ onto states that feature much longer lifetimes than the longitudinal deuterium Zeeman magnetization terms $3^{-1 / 2} / 2 \mathrm{D}_{\mathrm{z}}$ and $3^{-1 / 2} / 2 D_{\mathrm{z}}^{\prime}$ which relax with $T_{1}\left(\mathrm{D}_{\mathrm{z}}\right)=0.7 \mathrm{~s}$ in the $\mathrm{CD}_{2}$ group of perdeuterated ethanol-d6 under our experimental conditions.

Additionally, the terms $3^{-1 / 2} \mathrm{C}_{\mathrm{z}} \mathrm{D}_{\mathrm{z}}$ and $3^{-1 / 2} \mathrm{C}_{\mathrm{z}} \mathrm{D}_{\mathrm{z}}^{\prime}$ can also be transformed into a longer-lived spin order through crossrelaxation. However, such processes are rather inefficient compared to the projection. A theoretical treatment of longitudinal and transverse relaxation processes in $\mathrm{CD}_{n}$ groups with $n=2$ and 3 has been given by Kowalewski and co-workers. ${ }^{24,26,27}$ In conventional NMR without hyperpolarization, some effects are hard to detect. Through hyperpolarization by D-DNP, these become observable.

Certain relaxation pathways can be quite inefficient in $\mathrm{CD}_{2}$ systems leading to longer lifetimes of certain states.

To label the spin states of the $\mathrm{D}_{2}$ subsystem of the ${ }^{13} \mathrm{CD}_{2}$ group, the first and second numbers in the kets indicate the magnetic quantum numbers, $m_{z}(\mathrm{D})$ and $m_{z}\left(\mathrm{D}^{\prime}\right)=-1,0$, or 1 , of the two deuterons $\mathrm{D}$ and $\mathrm{D}^{\prime}:{ }^{24}$ There are six symmetrical states under permutation, which together constitute a sextet,

$$
\begin{aligned}
& \phi_{1}=|11\rangle, \\
& \phi_{2}=(|10\rangle+|01\rangle) / \sqrt{2}, \\
& \phi_{3}=(|1-1\rangle+|-11\rangle+2|00\rangle) / \sqrt{6}, \\
& \phi_{4}=(|1-1\rangle+|-11\rangle-|00\rangle) / \sqrt{3}, \\
& \phi_{5}=(|-10\rangle+|0-1\rangle) / \sqrt{2}, \\
& \phi_{6}=|-1-1\rangle .
\end{aligned}
$$

There are three states that are antisymmetrical under permutation, which together constitute a triplet,

$$
\begin{aligned}
& \phi_{7}=(|10\rangle-|01\rangle) / \sqrt{2}, \\
& \phi_{8}=(|1-1\rangle-|-11\rangle) / \sqrt{2}, \\
& \phi_{9}=(|0-1\rangle-|-10\rangle) / \sqrt{2} .
\end{aligned}
$$

These states are duplicated in the presence of a ${ }^{13} \mathrm{C}$ spin, which can adopt either the state $\alpha$ if $m_{z}\left({ }^{13} \mathrm{C}\right)=+\frac{1}{2}$ or $\beta$ if $m_{z}\left({ }^{13} \mathrm{C}\right)$ $=-\frac{1}{2}$, to yield 18 further states (denoted $\phi_{1-9}{ }^{\alpha}$ and $\phi_{1-9}{ }^{\beta}$ ). These 18 states constitute the energy levels shown in Fig. 2 with typical distributions of populations that can be achieved by hyperpolarization.

Diagonalizing the Liouvillian and analyzing its eigenvalues $^{28}$ reveals that long-lived spin order embracing a population imbalance between symmetric and antisymmetric states gives rise to long-lived states (in the case of anisotropic rotational diffusion). As these states involve population differences between the symmetric sextet and the antisymmetric triplet of the $\mathrm{D}_{2}$ subsystem, we shall refer to such states as a sextet-triplet imbalance (STI) — not to be confused with a triplet-singlet imbalance or TSI, as introduced by Levitt and co-workers, ${ }^{11}$ that can occur in systems with two equivalent $I=\frac{1}{2}$ spins. All six symmetric states have an equal excess population with respect to a demagnetized state, while all three antisymmetric states have an equal deficiency of populations, as shown in Fig. 2(c). This corresponds to an imbalance between the average populations of the symmetric and antisymmetric states of the spin system. The STI can be expressed as a linear combination of product operators,

$$
\begin{aligned}
& \mathrm{Q}_{\mathrm{STI}}{ }^{\mathrm{IP}}=\lambda_{1} 2^{-1 / 2} / 4 \mathrm{D}_{-} \mathrm{D}^{\prime}{ }_{+}+\lambda_{2} 2^{-1 / 2} / 4 \mathrm{D}_{+} \mathrm{D}^{\prime}{ }_{-} \\
& +\lambda_{3} 2^{-1 / 2} / 2 \mathrm{D}_{\mathrm{z}} \mathrm{D}_{\mathrm{z}}^{\prime}{ }+\lambda_{4} 2^{-1 / 2} / 4\left(\mathrm{D}_{-} \mathrm{D}^{\prime}{ }_{+}\right)^{2} \\
& +\lambda_{5} 2^{-1 / 2} / 4\left(\mathrm{D}_{+} \mathrm{D}_{-}^{\prime}\right)^{2} \\
& +\lambda_{6} 2^{-1 / 2} / 4\left[\mathrm{D}_{-} \mathrm{D}_{\mathrm{z}} \mathrm{D}^{\prime}{ }_{+} \mathrm{D}_{\mathrm{z}}^{\prime}+\mathrm{D}_{-} \mathrm{D}_{\mathrm{z}} \mathrm{D}^{\prime}{ }_{\mathrm{z}} \mathrm{D}^{\prime}{ }_{+}\right. \\
& \left.+\mathrm{D}_{\mathrm{z}} \mathrm{D}_{-} \mathrm{D}^{\prime}{ }_{+} \mathrm{D}_{\mathrm{z}}^{\prime}+\mathrm{D}_{\mathrm{z}} \mathrm{D}_{-} \mathrm{D}_{\mathrm{z}^{\prime}} \mathrm{D}^{\prime}{ }_{+}\right] \\
& +\lambda_{7} 2^{-1 / 2} / 4\left[\mathrm{D}_{+} \mathrm{D}_{\mathrm{z}} \mathrm{D}^{\prime}{ }_{-} \mathrm{D}_{\mathrm{z}}^{\prime}+\mathrm{D}_{+} \mathrm{D}_{\mathrm{z}} \mathrm{D}_{\mathrm{z}}^{\prime} \mathrm{D}^{\prime}{ }_{-}\right. \\
& \left.+\mathrm{D}_{\mathrm{z}} \mathrm{D}_{+} \mathrm{D}_{-}^{\prime} \mathrm{D}_{\mathrm{z}}^{\prime}+\mathrm{D}_{\mathrm{z}} \mathrm{D}_{+} \mathrm{D}_{\mathrm{z}}^{\prime} \mathrm{D}_{-}^{\prime}\right] \\
& +\lambda_{8} 2^{-1 / 2} / 6\left[-6 \mathrm{D}_{\mathrm{z}}{ }^{2}-6 \mathrm{D}_{\mathrm{z}}{ }^{\prime 2}+9\left(\mathrm{D}_{\mathrm{z}} \mathrm{D}_{\mathrm{z}}{ }^{\prime}\right)^{2}+4 \mathrm{E}\right] \text {, }
\end{aligned}
$$

where $\mathrm{E}$ is the identity operator, and $\lambda_{1}=\lambda_{2}=\lambda_{3}=\lambda_{4}=\lambda_{5}$ $=\lambda_{6}=\lambda_{7}=\lambda_{8}=8^{-1 / 2}$, which is the total norm of $\mathrm{Q}_{\mathrm{STI}}{ }_{\mathrm{IP}}$.

Another set of operators $Q_{\text {STI }}$ are in antiphase with respect to the ${ }^{13} \mathrm{C}$ nucleus,

$$
\mathrm{Q}_{\mathrm{STI}}{ }^{\mathrm{AP}}=\mathrm{Q}_{\mathrm{STI}}{ }^{\mathrm{IP}} \mathrm{C}_{\mathrm{Z}}
$$



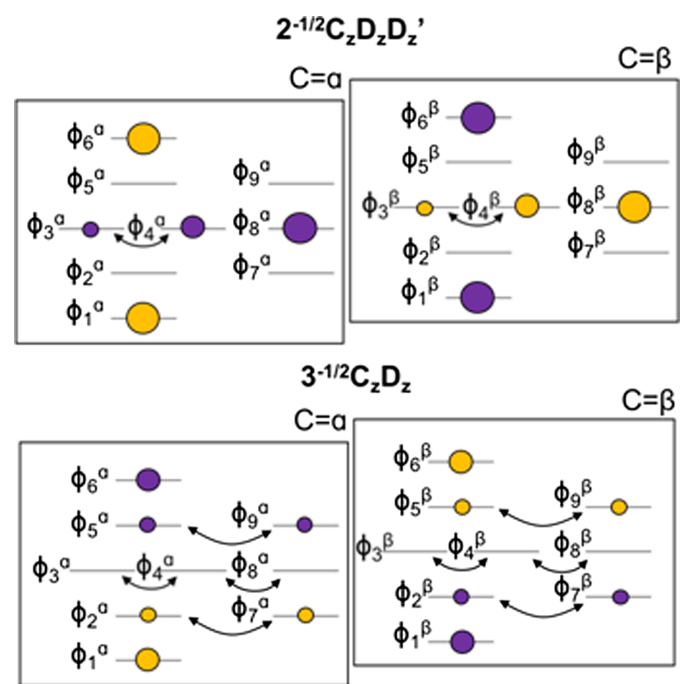

\section{Sextet Triplet Imbalance}

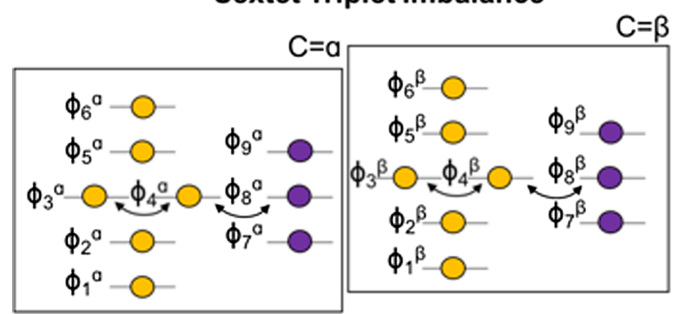

Sextet Triplet Imbalance in Antiphase

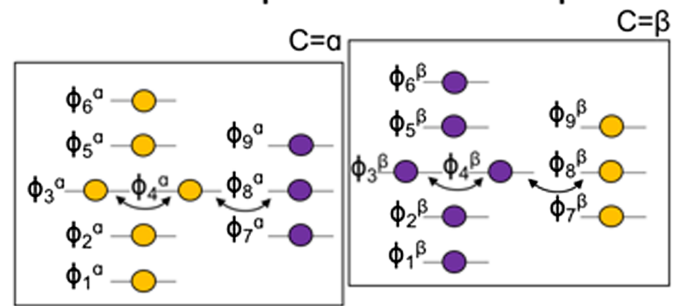

FIG. 2. Energy-level diagrams of selected states of a ${ }^{13} \mathrm{CD}_{2}$ spin system. Black arrows represent zero-quantum coherences between almost degenerate pairs of spin states. These states are actually split by ${ }^{2} J_{\mathrm{DD}} \approx-0.28 \mathrm{~Hz}$. The size of the spheres indicates the populations, with yellow for positive and purple for negative deviations from a demagnetized state.

Note that the terms such as $2^{-1 / 2} \mathrm{C}_{\mathrm{z}} \mathrm{D}_{\mathrm{z}} \mathrm{D}_{\mathrm{z}}^{\prime}$, which appear at the end of cross-polarization, are included in $\mathrm{Q}_{\mathrm{STI}}{ }^{\mathrm{AP}}$, so that this eigenoperator is partly populated immediately after dissolution. Defining a projection operator $\left|\mathrm{Q}_{\mathrm{STI}}{ }^{\mathrm{AP}}><\mathrm{Q}_{\mathrm{STI}}{ }_{\mathrm{AP}}\right|$ we find that the projection of $2^{-1 / 2} \mathrm{C}_{\mathrm{z}} \mathrm{D}_{\mathrm{Z}} \mathrm{D}_{\mathrm{z}}^{\prime}$ onto $\mathrm{Q}_{\mathrm{STI}}{ }^{\mathrm{AP}}$ gives a coefficient $2^{-1 / 2} / 2$. (Note that this is also true for all other operators that constitute $\mathrm{Q}_{\mathrm{STI}}{ }_{\mathrm{IP}}$ and $\mathrm{Q}_{\mathrm{STI}}{ }_{\mathrm{AP}}$. Yet, these are not as strongly populated as $3^{-1 / 2} \mathrm{C}_{\mathrm{z}} \mathrm{D}_{\mathrm{z}}, 3^{-1 / 2} \mathrm{C}_{\mathrm{z}} \mathrm{D}^{\prime}{ }_{\mathrm{z}}$, and $2^{-1 / 2} \mathrm{C}_{\mathrm{z}} \mathrm{D}_{\mathrm{z}} \mathrm{D}^{\prime}{ }_{\mathrm{z}}$ according to our simulations.) Thus, $\mathrm{CP}$ of the ${ }^{13} \mathrm{C}$ nucleus of a $\mathrm{CD}_{2}$ group instantaneously leads to the occurrence of the $\mathrm{Q}_{\mathrm{STI}}{ }^{\mathrm{AP}}$ term. Taking into account that approximately $15 \%-20 \%$ of the $2^{-1 / 2} \mathrm{C}_{\mathrm{z}} \mathrm{D}_{\mathrm{z}} \mathrm{D}_{\mathrm{z}}^{\prime}$ term is populated during multiple contact CPs, one may estimate that about $10 \%$ of the magnetization after CP is present in the form of $\mathrm{Q}_{\mathrm{STI}}{ }^{\mathrm{AP}}$ due to the projection of $2^{-1 / 2} \mathrm{C}_{\mathrm{z}} \mathrm{D}_{\mathrm{z}} \mathrm{D}^{\prime}{ }_{\mathrm{Z}}$. Other processes like cross relaxation of $3^{-1 / 2} \mathrm{C}_{\mathrm{z}} \mathrm{D}_{\mathrm{z}}$ and $3^{-1 / 2} \mathrm{C}_{\mathrm{z}} \mathrm{D}^{\prime}{ }_{\mathrm{z}}$ will further contribute.

If the unique axes of the two Q-tensors were parallel, the symmetric states $\left(\phi_{1}-\phi_{6}\right)$ would be isolated from the antisymmetric states $\left(\phi_{7}-\phi_{9}\right)$, since the matrix elements connecting these two sets of states would vanish. This case has been treated by Poupko et al. ${ }^{29} \mathrm{~A}$ phenomenon similar to longlived states known for spin $\frac{1}{2}$ systems arises, which makes quadrupolar relaxation largely ineffective.

The relaxation properties of $\mathrm{Q}_{\mathrm{STI}}^{\mathrm{IP}}$ and $\mathrm{Q}_{\mathrm{STI}}{ }^{\mathrm{AP}}$ are best understood by examining the relaxation matrix. In Fig. 3(a) this matrix is depicted for isotropic rotational diffusion. The Q-tensors are assumed to be cylindrical $(\eta=0)$ with their unique axes aligned along the $\mathrm{C}-\mathrm{D}$ bond axes. Such a geometry leads to a mixing of the symmetric $\left(\phi_{1}-\phi_{6}\right)$ and antisymmetric $\left(\phi_{7}-\phi_{9}\right)$ states, as highlighted by the red dashed boxes in Fig. 3(a).

If rotational diffusion is anisotropic, these interconnecting matrix elements are attenuated, so that the symmetric and antisymmetric manifolds become largely isolated. ${ }^{29}$ Assuming a
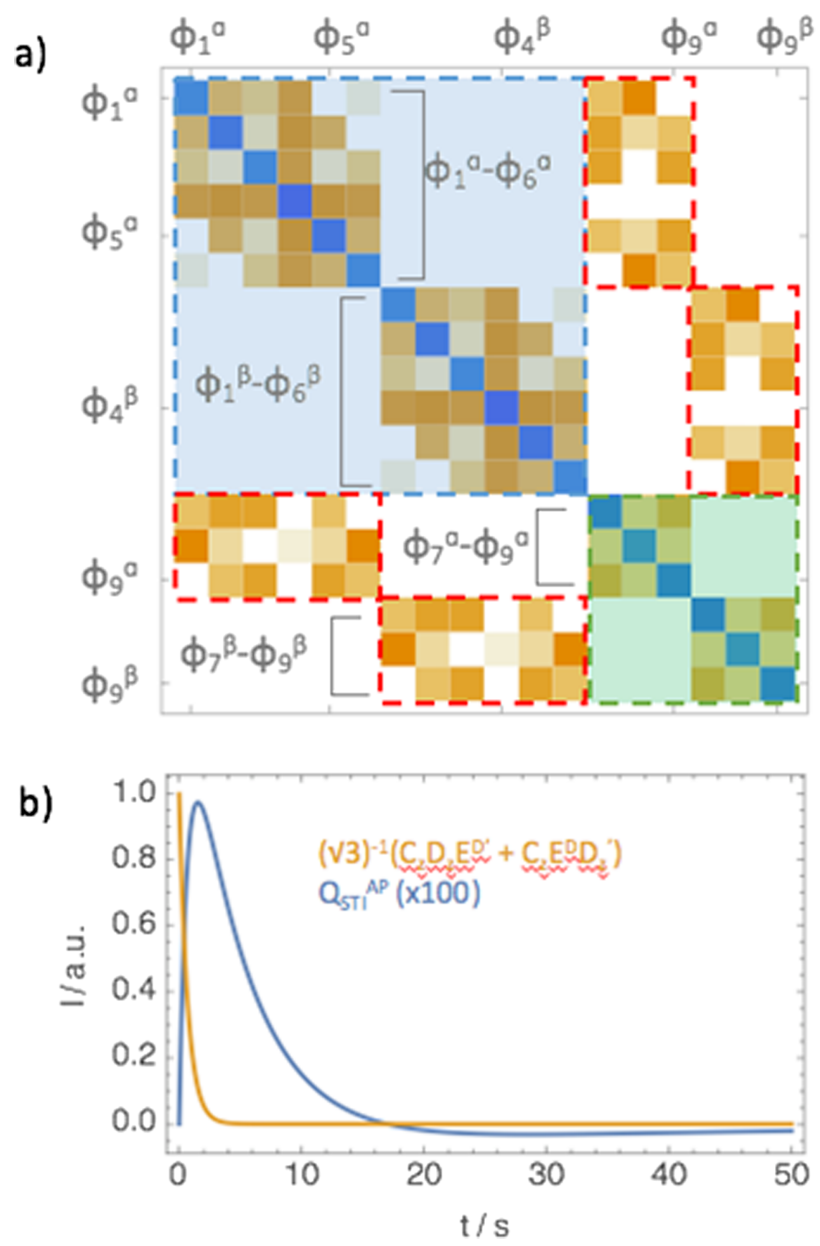

FIG. 3. (a) Typical Liouville relaxation matrix due to quadrupolar couplings in $\mathrm{CD}_{2}$ system for the case of isotropic rotational diffusion. Negative and positive elements are represented in blue and various shades of brown. The matrix elements connecting symmetric (blue area) and antisymmetric (green area) manifolds are highlighted by the red dashed squares. For the sake of clarity, the relaxation matrix only shows populations, but in our simulations the entire Liouville space was taken into account, including all coherence orders. We did not assume that the two deuterons are magnetically equivalent. To treat the general case, we did not employ the simplifications proposed in Ref. 26. (b) Relaxation of the expectation value of the operator $3^{-1 / 2} \mathrm{C}_{\mathrm{z}} \mathrm{D}_{\mathrm{z}}+3^{-1 / 2} \mathrm{C}_{\mathrm{z}} \mathrm{D}_{\mathrm{z}}^{\prime}$ and the subsequent build-up of a sextet-triplet imbalance $\left(\mathrm{Q}_{\mathrm{STI}}{ }_{\mathrm{AP}}\right)$ for anisotropic rotational diffusion $\left(5 \tau_{\perp}=\tau_{\|}\right)$. 
symmetric top, we find that cross relaxation between symmetric and antisymmetric states is largely ineffective if $\tau_{\|}>\tau_{\perp}$, where the latter refers to motions around an axis perpendicular to the plane spanned by the two C-D bonds, while the former denotes the rotation around an axis that bisects the $\mathrm{D}-\mathrm{C}-\mathrm{D}^{\prime}$ angle.

The rotational diffusion of ethanol- $\mathrm{d}_{6}$ defined by $\tau_{\perp}$ is fastest and therefore gives the weakest contribution to the relaxation rates. The Q-tensor elements parallel to this axis contribute predominantly to relaxation. These are symmetric with respect to spin exchange and hence do not cause any cross relaxation between symmetric and antisymmetric spin manifolds. ${ }^{30}$ In other words, the projections of the two Q-tensors onto the main diffusion axis (which is perpendicular to the D-C-D' plane) are equal, so that symmetric and antisymmetric spin states are dynamically isolated. Additionally, an asymmetry of the Q-tensors $(\eta \neq 0)$ will further diminish the influence of matrix elements connecting symmetric and antisymmetric spin states. As these matrix elements diminish, the population imbalance between the two manifolds will gain in lifetime. This is what gives rise to the long lifetime of an STI.

Bernatowicz and Szymański ${ }^{31,32}$ have discussed related effects on the ${ }^{15} \mathrm{~N}$ line shape due to transverse relaxation in azide $\left[{ }^{14} \mathrm{~N}^{15} \mathrm{~N}^{14} \mathrm{~N}\right]^{-}$which is formally similar (two spin1 nuclei and one spin $\frac{1}{2}$ nucleus) to our case of $\mathrm{D}^{13} \mathrm{CD}^{\prime}$. In both cases, the energy levels $\phi_{3}, \phi_{4}$, and $\phi_{8}$ are coupled via zero quantum coherences $\left(\left|\phi_{3}\right\rangle<\phi_{8}|,| \phi_{4}\right\rangle<\phi_{8} \mid$, etc.), as indicated by the black arrows in Fig. 2. Bernatowicz and Szymański ${ }^{31,32}$ distinguish between magnetic (non-) equivalence and nuclear permutation symmetry of the two ${ }^{14} \mathrm{~N}$ nuclei with a mutual coupling constant of ${ }^{2} J\left({ }^{14} \mathrm{~N},{ }^{14} \mathrm{~N}^{\prime}\right)$ $=11.54 \mathrm{~Hz}$. In our case, the two deuterons likewise show scalar coupling, with a constant of ${ }^{2} J\left(\mathrm{D}, \mathrm{D}^{\prime}\right)={ }^{2} J_{\mathrm{DD}} \approx-0.28 \mathrm{~Hz}$ (cf. Fig. 2). However, the zero quantum coherences between symmetric $\left(\mid \phi_{3}>\right)$ and $\left(\mid \phi_{4}>\right)$ and antisymmetric states $\left(\mid \phi_{8}>\right)$ cannot cause a flow of populations, since such processes remain symmetry forbidden under the assumption that the two Q-tensors are aligned, either in the linear $\left[{ }^{14} \mathrm{~N}^{15} \mathrm{~N}^{14} \mathrm{~N}\right]^{-}$ion or because of motional averaging in $\mathrm{D}^{13} \mathrm{CD}^{\prime}$ in ethanol- $\mathrm{d}_{6}$. If the (quadrupolar) relaxation were very slow, these coherences could be neglected since they oscillate with frequencies $\pm 3\left({ }^{2} J_{\mathrm{DD}}\right)$. However, the off-diagonal relaxation matrix elements involving the above-mentioned zero-quantum coherences might be of the order of the quadrupolar relaxation rate constants, so that the influence of such effects may become significant. This phenomenon is likely to be the limiting factor of the lifetimes of the STI. This effect can be readily investigated by simulations that take into account the complete set of spin states of the $13 \mathrm{CDD}^{\prime}$ system. Simulations using several values of the quadrupolar constants and scalar coupling constants ${ }^{2} J\left(D, D^{\prime}\right)$ did not reveal any significant effects on the relaxation matrix.

Note that the three-spin density operator term $2^{-1 / 2} \mathrm{C}_{\mathrm{z}} \mathrm{D}_{\mathrm{z}} \mathrm{D}^{\prime}{ }_{\mathrm{z}}$ that is present after CP-DNP is readily projected onto $\mathrm{Q}_{\mathrm{STI}}{ }_{\mathrm{IP}}$ and $\mathrm{Q}_{\mathrm{STI}}{ }^{\mathrm{AP}}$, while the two-spin terms $3^{-1 / 2} \mathrm{C}_{\mathrm{z}} \mathrm{D}_{\mathrm{Z}}$ $+3^{-1 / 2} \mathrm{C}_{\mathrm{z}} \mathrm{D}_{\mathrm{z}}^{\prime}$ can be partly converted into long-lived spin order by cross-relaxation (see Fig. 3(b) for simulations of the build-up and decay).

\section{RESULTS AND DISCUSSION}

In ordinary ${ }^{13} \mathrm{C}$ spectra in solution at room temperature, the high temperature approximation is fulfilled, so that the ${ }^{13} \mathrm{CD}_{2}$ group of perdeuterated ethanol- $\mathrm{d}_{6}$ gives rise to a (nonbinomial) 1:2:3:2:1 pentet that results from the convolution of a 1:1:1 triplet with another 1:1:1 triplet with the same splitting ${ }^{2} \mathrm{~J}\left(\mathrm{D},{ }^{13} \mathrm{C}\right)=18.5 \mathrm{~Hz}$. In Fig. 4 the experimentally detected ${ }^{13} \mathrm{C}$ pentet of hyperpolarized perdeuterated ethanol- $\mathrm{d}_{6}$ is shown at different intervals after dissolution. Despite the slow transfer to the NMR spectrometer that required $10 \mathrm{~s}$, the ${ }^{13} \mathrm{C}$ signal enhancement compared to thermal equilibrium signal was estimated to be $\varepsilon=3900$ immediately after injection.

The presence of hyperpolarized STI states involving deuterium spins is revealed by the relative amplitudes of the multiplet components depicted in Fig. 4. The intensities are denoted $L_{1}$ to $L_{5}$ from low to high frequency. In the hyperpolarized sample, one observes an asymmetry of the signal where the low-field transitions $\left(\mathrm{L}_{1}\right.$ and $\left.\mathrm{L}_{2}\right)$ are enhanced compared to the high temperature intensity ratios $1: 2: 3: 2: 1$, while the high field-transitions $\left(\mathrm{L}_{5}\right.$ and $\left.\mathrm{L}_{6}\right)$ are attenuated. Additionally, $\mathrm{L}_{3}$ is reduced with respect to the outer transitions, while $\mathrm{L}_{2} / \mathrm{L}_{1}>2$ and $\mathrm{L}_{4} / \mathrm{L}_{5}>2$. This asymmetry is reminiscent of similar observations for pairs of ${ }^{13} \mathrm{C}$ spins $I=S=1 / 2$ that have been analyzed recently by Vuichoud et al. ${ }^{33}$ In a $\mathrm{CD}_{2}$ system, the asymmetry can be traced back to $3^{-1 / 2}\left(\mathrm{C}_{\mathrm{z}} \mathrm{D}_{\mathrm{z}}+\mathrm{C}_{\mathrm{z}} \mathrm{D}_{\mathrm{z}}{ }^{\prime}\right)$ and $2^{-1 / 2} \mathrm{C}_{\mathrm{z}} \mathrm{D}_{\mathrm{z}} \mathrm{D}^{\prime}{ }_{\mathrm{z}}$ terms as explained in the section titled "Theory." These lead to STIs, which determine the intensities of the five transitions in the ${ }^{13} \mathrm{C}$ pentet after dissolution. As they relax slower than both $3^{-1 / 2} / 2 \mathrm{D}_{\mathrm{z}}$ and $3^{-1 / 2} / 2 \mathrm{D}_{\mathrm{z}}^{\prime}$ terms, the effect of the STI is observable long after dissolution. ${ }^{24,26,27}$

Simulations of the time evolution by the SpinDynamica software yield the signals shown in yellow in Fig. 4. These simulations assume that the initial density operator (immediately after dissolution) contains a mixture of $2^{1 / 2} / 3 \mathrm{C}_{\mathrm{z}}, 3^{-1 / 2} \mathrm{C}_{\mathrm{z}} \mathrm{D}_{\mathrm{z}}$, a)
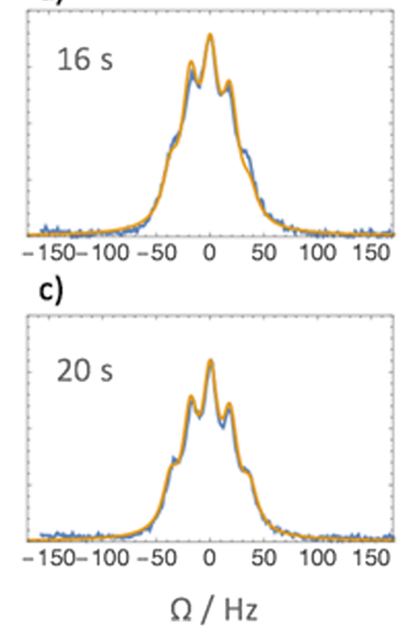

b)

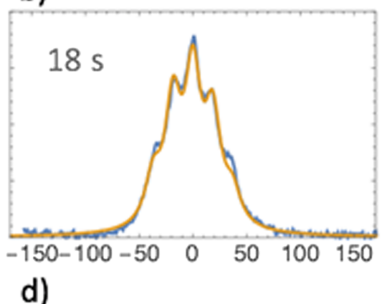

d)

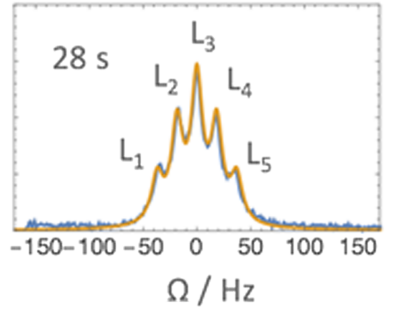

FIG. 4. Blue: Experimental ${ }^{13} \mathrm{C}$ multiplets of the ${ }^{13} \mathrm{CD}_{2}$ group of hyperpolarized ethanol-d6, detected at intervals of 16, 18, 20, and $28 \mathrm{~s}$ after dissolution. Yellow: Simulations by SpinDynamica. The individual transitions are labeled $\mathrm{L}_{1}$ to $\mathrm{L}_{5}$ from low to high field (i.e., from high to low frequencies, see bottom right). In the high temperature approximation that prevails at room temperature, the $\mathrm{CD}_{2}$ group gives rise to a symmetrical 1:2:3:2:1 pentet with a splitting ${ }^{1} J\left(\mathrm{D},{ }^{13} \mathrm{C}\right)=18.5 \mathrm{~Hz}$. 
$3^{-1 / 2} \mathrm{C}_{\mathrm{z}} \mathrm{D}_{\mathrm{z}}^{\prime}$, and $2^{-1 / 2} \mathrm{C}_{\mathrm{z}} \mathrm{D}_{\mathrm{z}} \mathrm{D}_{\mathrm{z}}^{\prime}$ terms. The simulations reproduce the experimental time evolution of the detected carbon signal remarkably well. Note that the ethanol sample under investigation is not enriched in ${ }^{13} \mathrm{C}$, hence $99 \%$ of the ethanol molecules in the sample do not contribute to the observed STI.

After a sufficient interval, all terms containing deuterium operators relax to their equilibrium values and only $\mathrm{C}_{\mathrm{Z}}$ magnetization remains (which is initially populated through $\mathrm{CP}$ ) and the high-temperature intensity ratio of 1:2:3:2:1 is recovered. This can be observed in Fig. 4(d).

To assess the lifetime of the total deuterium polarization after dissolution, we fitted the individual lines $\mathrm{L}_{1}$ to $\mathrm{L}_{5}$ of the ${ }^{13} \mathrm{C}$-pentet to five Lorentzians, using the so-called quasiNewton Broyden-Fletcher-Goldfarb-Shanno algorithm, ${ }^{34}$ as implemented in Scilab. ${ }^{35}$ This method allows one to determine the intensities of the individual lines despite extensive overlap, as observed in our experiments (Fig. 4). The decays of the intensities of the five lines of the pentet are shown in Fig. 5(a). The asymmetry due to the deuterium hyperpolarization can be expressed by the differences $\left(\mathrm{L}_{1}-\mathrm{L}_{5}\right)$ and $\left(\mathrm{L}_{2}-\mathrm{L}_{4}\right)$ as well as by the ratio between the central and the outer transitions (see labels in Fig. 4). By defining an overall asymmetry $A=\left(L_{1}\right.$ $\left.+\mathrm{L}_{2}-\mathrm{L}_{4}-\mathrm{L}_{5}\right) / \mathrm{L}_{3}$, we can indirectly characterize the deuterium polarization. This asymmetry decays monoexponentially as shown in Fig. 5(b). The characteristic relaxation time constant was fitted to be $T_{\mathrm{STI}}=15.9 \pm 5.4 \mathrm{~s}$. This decay time corresponds to an effective lifetime of long-lived spin order. As single-spin Zeeman magnetization $\mathrm{D}_{\mathrm{z}}=3^{-1 / 2} / 2 \mathrm{D}_{\mathrm{z}}$ relaxes with a $T_{1}\left(\mathrm{D}_{\mathrm{z}}\right)=0.7 \mathrm{~s}$ under the
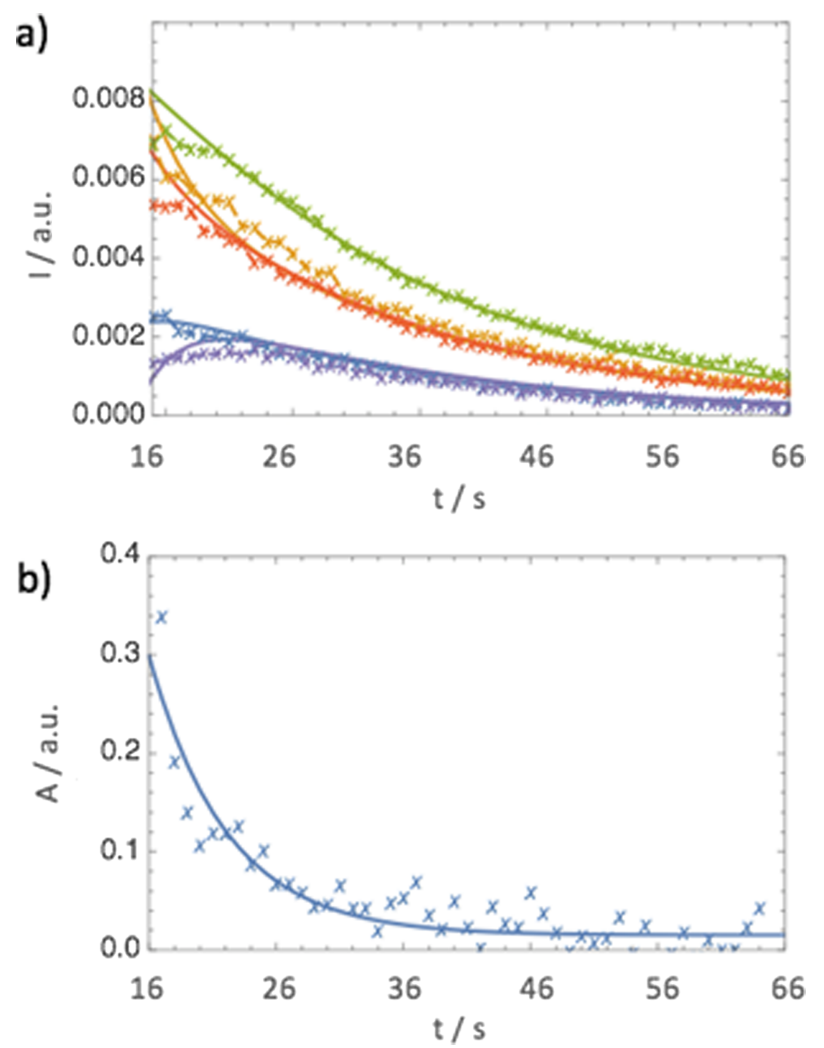

FIG. 5. (a) Decay of the individual lines $\mathrm{L}_{1}$ to $\mathrm{L}_{5}$ of the ${ }^{13} \mathrm{C}$ pentet of the $\mathrm{CD}_{2}$ moiety of ethanol-d6 after dissolution. Solid lines stem from simulations of the relaxation process. (b) Time-dependence of the asymmetry of the pentet defined as $A=\left(L_{1}+L_{2}-L_{4}-L_{5}\right) / L_{3}$ (cf. Fig. 4).

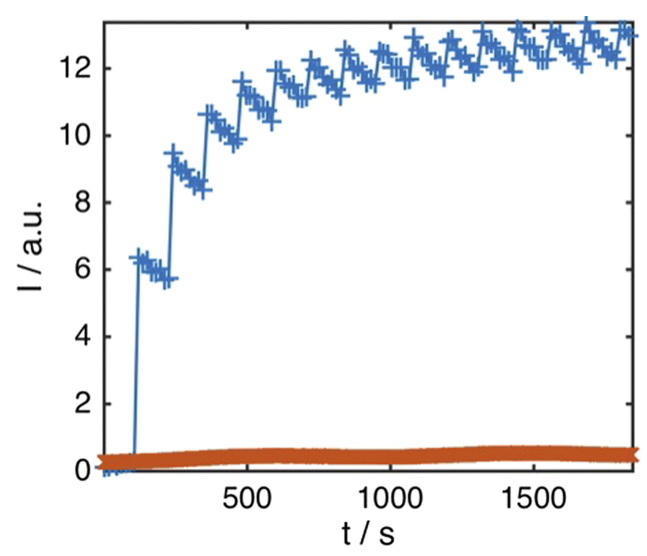

FIG. 6. ${ }^{13} \mathrm{C}$ signal intensities of ethanol-d6 at $1.2 \mathrm{~K}$ for direct polarization (orange) and $\mathrm{CP}$ (blue).

same conditions ${ }^{19}$ the extension of the lifetime is about $\kappa=T_{\mathrm{STI}} / \mathrm{T}_{1}\left(D_{\mathrm{z}}\right)=21.4$, while $T_{1}\left(\mathrm{C}_{\mathrm{z}}\right)=23 \mathrm{~s}$. By calculating the ratio $\mathrm{R}=\left(\mathrm{L}_{1}+\mathrm{L}_{5} / \mathrm{L}_{2}+\mathrm{L}_{3}+\mathrm{L}_{4}\right)$, we can determine the fraction of the STIs to be $\vartheta=1-\mathrm{R} / 3$ as the antisymmetric spin states contribute only to $\mathrm{L}_{2}$ to $\mathrm{L}_{4}$. We determined approximately $\vartheta=15 \%$ of the total carbon magnetization after the transfer delay. This is in agreement with the value estimated from our numerical simulations.

This phenomenon is based on the dynamic isolation of symmetric and anti-symmetric spin manifolds, which is the principle behind many long-lived states (LLS). ${ }^{30,36}$

In direct polarization experiments without $\mathrm{CP}$, we did not observe any asymmetry since direct polarization of deuterium (including multi-spin terms), like direct polarization of ${ }^{13} \mathrm{C}$, is rather inefficient compared to $\mathrm{CP}$ (see Fig. 6). Note that the multispin order terms $\mathrm{C}_{\mathrm{z}} \mathrm{D}_{\mathrm{z}}, \mathrm{C}_{\mathrm{z}} D_{\mathrm{z}}^{\prime}$, and $\mathrm{C}_{\mathrm{z}} \mathrm{D}_{\mathrm{z}} \mathrm{D}_{\mathrm{z}}^{\prime}$ that we discuss are not due to DNP but are created during cross-polarization (CP) at low temperature because the RF field strength applied to the ${ }^{13} \mathrm{C}$ channel is not sufficient to quench the dipolar couplings between ${ }^{13} \mathrm{C}$ and $\mathrm{D}$. We intend to detect ${ }^{2} \mathrm{H}$ signals at $1.2 \mathrm{~K}$ to quantify the populations of various terms during CP. Further, we want to emphasize that the absence of any asymmetry in direct polarization experiments shows that crossrelaxation of $2^{1 / 2} / 3 C_{\mathrm{Z}}$ magnetization into $\mathrm{Q}_{\mathrm{STI}}{ }_{\mathrm{IP}}$ and $\mathrm{Q}_{\mathrm{STI}}{ }^{\mathrm{AP}}$ is quite inefficient. The observed asymmetry is not induced by the relaxation of the carbon nucleus.

\section{CONCLUSIONS}

The cross relaxation and projection of the initial of $2^{1 / 2} / 3 \mathrm{C}_{\mathrm{z}}, 3^{-1 / 2} \mathrm{C}_{\mathrm{z}} \mathrm{D}_{\mathrm{z}}, 3^{-1 / 2} \mathrm{C}_{\mathrm{z}} \mathrm{D}_{\mathrm{z}}^{\prime}$, and $2^{-1 / 2} \mathrm{C}_{\mathrm{z}} \mathrm{D}_{\mathrm{z}} \mathrm{D}_{\mathrm{z}}^{\prime}$ terms onto $\mathrm{Q}_{\mathrm{STI}}{ }_{\mathrm{IP}}$ and $\mathrm{Q}_{\mathrm{STI}}{ }_{\mathrm{AP}}$ lead to a population of STI terms on the order of a few percent of the initial $\mathrm{C}_{\mathrm{z}}$ term directly after dissolution. (This explains the modest ${ }^{13} \mathrm{C}$ enhancement factor $\varepsilon=3900$ as a large fraction of the multi-spin terms relaxes quite fast during the transfer after dissolution, which is typical for quadrupolar nuclei.) Only CP-based DNP can sufficiently boost the intensity to observe these longer lived states. The entire experiment described here can be summarized as follows: (i) Multi-spin terms are populated during $\mathrm{CP}$ at cryogenic temperatures, (ii) these terms project and cross-relax onto the STIs, (iii) the STIs are preserved upon dissolution, 
(iv) the STI is measurable indirectly via the asymmetry of ${ }^{13} \mathrm{C}$ spectrum of the $\mathrm{CD}_{2}$ group.

In conclusion, we have shown how one can "indirectly" hyperpolarize deuterium nuclei coupled to a ${ }^{13} \mathrm{C}$ nucleus via $\mathrm{CP}$ from ${ }^{1} \mathrm{H}$ to ${ }^{13} \mathrm{C}$ using weak $r f$ amplitudes. Furthermore, it has been shown that some constituents of the density operator of a $\mathrm{CD}_{2}$ system can have lifetimes that, although shorter than $T_{1}\left(\mathrm{C}_{\mathrm{z}}\right)=23 \mathrm{~s}$ for the case at hand, are much longer than $T_{1}\left(\mathrm{D}_{\mathrm{z}}\right)=0.7 \mathrm{~s}$ of the Zeeman polarization of individual deuterium nuclei in the same system. These observations expand the scope of DNP by adding another nucleus to the list of possible observables. Thus, deuterium-based NMR with improved sensitivity on longer time scales becomes possible.

\section{EXPERIMENTAL}

DNP experiments were performed on a Bruker prototype operating at $6.7 \mathrm{~T}$ and $1.2 \mathrm{~K}$. The ${ }^{13} \mathrm{C}$ hyperpolarization was obtained via cross polarization from ${ }^{1} \mathrm{H}$ to ${ }^{13} \mathrm{C}$. ${ }^{2}$ TEMPOL (4-hydroxy-2,2,6,6-tetramethylpiperidine-1-oxyl) was used as a polarizing agent.

The optimal amplitude of the spin-locking rf field was found to be $\gamma \mathrm{B}_{1}^{\mathrm{C}} /(2 \pi)=50 \mathrm{kHz}$ for a duration of the Hartmann-Hahn contact of $\tau_{\mathrm{SL}}=5 \mathrm{~ms}$. The ${ }^{13} \mathrm{C}$ build-up curve for direct polarization and for $\mathrm{CP}$ is shown in Fig. 6.

A continuous $\mu \mathrm{W}$ field with a power of $34 \mathrm{~mW}$ at $188 \mathrm{GHz}$ at the position of the sample, modulated with a saw-tooth function over a range of $100 \mathrm{MHz}$ with a modulation frequency of $2 \mathrm{kHz}$, was used to saturate part of the EPR spectrum of the free radicals. The microwave was switched off $1 \mathrm{~s}$ before every $\mathrm{CP}$ step to allow the unpaired electrons to relax back to equilibrium.

Dissolution and transfer to the detection NMR spectrometer were performed with $5 \mathrm{ml} \mathrm{D}_{2} \mathrm{O}$ at 10.5 bars heated to $180{ }^{\circ} \mathrm{C}$, which was sprayed onto the frozen sample. The transfer of the dissolved hyperpolarized liquid to the NMR spectrometer took $10 \mathrm{~s}$. The proton polarization that could be reached with our setup at $1.2 \mathrm{~K}$ was determined to be $P\left({ }^{1} \mathrm{H}\right)=81 \%$ by comparison with a thermally equilibrated signal. The carbon polarization was determined to be $P\left({ }^{13} \mathrm{C}\right)=49 \%$ after CP. However, due to a superposition of antiphase terms, positive and negative lines may partly cancel.

\section{Sample preparation}

A $50 \mathrm{mM}$ solution of TEMPOL in a mixture of $60 \%$ ethanol- $\mathrm{d}_{6}, 30 \%$ glycerol-d8, and $10 \% \mathrm{H}_{2} \mathrm{O}$ was shock-frozen in liquid nitrogen. The resulting glass was then transferred to the DNP polarizer. After dissolution with $5 \mathrm{ml} \mathrm{D}_{2} \mathrm{O}$, the final ethanol- $\mathrm{d}_{6}$ concentration was $1.04 \mathrm{mM}$.

\section{Detection}

The signals were detected on a Bruker $400 \mathrm{MHz}$ spectrometer using a $10 \mathrm{~mm}$ BBO broadband probe at room temperature. Pulses with $10^{\circ}$ angles were used at intervals of $1 \mathrm{~s}$, with an acquisition time of $0.3 \mathrm{~s}$. The spectra were processed with NMRPipe $^{37}$ using zero-filling but without apodization prior to analysis to avoid distorting the line shapes.

\section{ACKNOWLEDGMENTS}

Dedicated to Professor Anil Kumar, Indian Institute of Science, Bangalore, on the occasion of his $75^{\text {th }}$ birthday.

The authors want to thank Dr. Jean-Nicolas Dumez for helpful discussions; Sven Sieber, Michael Schenkel, Rolf Hensel, Jacco van Beek, Ion Prisucaru, and Armin Purea for contributions to the system design and implementation; and Frank Engelke, Pietro Lendi, Klemens Kessler, Daniel Eckert, Daniel Guy Baumann, Dirk Wilhelm, Roberto Seydoux, Uwe Wagner, Cengiz Cetrefli, Tonio Gianotti, and Jörg Hinderer for contributions to the system specification. This work was supported by the French CNRS and the European Research Council (ERC contract "Dilute para-water" and 2F4BIODYN, S.F.C.). Some of the work in this article employed the SpinDynamica code for Mathematica, programmed by Malcolm H. Levitt, with contributions from Jyrki Rantaharju, Andreas Brinkmann, and Soumya Singha Roy, available at www.SpinDynamica.soton.ac.uk.

\section{APPENDIX A: OPERATOR NOTATION AND NORMALIZATION}

We define the 18-dimensional operators as the following outer products:

$$
\begin{aligned}
& 3^{-1 / 2} / 2 \mathrm{D}_{\mathrm{z}} \equiv 3^{-1 / 2} / 2 \underline{\underline{\mathrm{E}^{\mathrm{C}}}} \otimes \underline{\underline{\mathrm{D}}} \otimes \underline{\underline{\underline{z}}} \otimes \underline{\underline{\mathrm{E}^{\mathrm{D}^{\prime}}}} \\
& 3^{-1 / 2} / 2 \mathrm{D}_{\mathrm{z}}^{\prime} \equiv 3^{-1 / 2} / 2 \underline{\underline{\mathrm{E}^{\mathrm{C}}}} \otimes \underline{\underline{\mathrm{E}^{\mathrm{D}}}} \otimes \underline{\underline{\mathrm{D}^{\prime}}} \underline{\underline{\underline{z}}} \\
& 2^{-1 / 2} / 3 \mathrm{C}_{\mathrm{z}} \equiv 2^{-1 / 2} / \underline{\underline{\underline{\mathrm{C}}}} \underline{\underline{\underline{z}}} \otimes \underline{\underline{\mathrm{E}^{\mathrm{D}}}} \otimes \underline{\underline{\mathrm{E}^{\mathrm{D}^{\prime}}}}
\end{aligned}
$$

where the doubly underlined operators represent the three (in the case of D) or two (in the case of C) dimensional matrix representations of the single spin operators. E denotes identity operators. Product operators in Liouville space involve simple matrix products,

$$
3^{-1 / 2} C_{z} D_{z}=3^{-1 / 2}\left(C_{z} \cdot D_{z}\right) .
$$

The norm $\|A\|$ of an operator $A$ is defined as the square root of the scalar product $(A \mid A)=\operatorname{Tr}\left\{A^{\dagger} \cdot A\right\}:\|A\|^{2}=(A \mid A)$.

\section{APPENDIX B: RELAXATION RATES}

The lifetimes of the $\mathrm{Q}_{\mathrm{STI}}{ }^{\mathrm{IP}}$ and $\mathrm{Q}_{\mathrm{STI}}{ }^{\mathrm{AP}}$ operators are almost the same (except if the ${ }^{13} \mathrm{C}$ nucleus has a large CSA relaxation rate at high field) and depend strongly on the anisotropy of the rotational diffusion of the molecule. For two axially symmetric $Q$-tensors, the quadrupolar relaxation rate of the $\mathrm{Q}_{\mathrm{STI}}{ }_{\mathrm{IP}}$ and $\mathrm{Q}_{\mathrm{STI}}{ }^{\mathrm{AP}}$ terms is quite small but does not vanish,

$$
R\left(Q_{S T I}^{I P}\right)=R\left(Q_{S T I}^{A P}\right)=\frac{3 \tau_{\perp} \tau_{\|}}{4 \tau_{\|}+\tau_{\perp}} \omega_{Q}^{2},
$$

where $\omega_{Q}$ denotes the quadrupolar coupling constant in units of angular frequency. This rate decreases if $\tau_{\|}>\tau_{\perp}$. Longitudinal $\mathrm{D}_{\mathrm{z}}$ Zeeman order decays with a rate

$$
\begin{aligned}
R\left(D_{z}\right)= & {\left[\frac{3}{8} \frac{\tau_{\|}^{3}}{\left(\tau_{\|}+\tau_{\perp} / 4\right)\left(\tau_{\|}+\tau_{\perp}\right)}+\frac{3}{4} \frac{\tau_{\|}^{2} \tau_{\perp}}{\left(\tau_{\|}+\tau_{\perp} / 4\right)\left(\tau_{\|}+\tau_{\perp}\right)}\right.} \\
& \left.+\frac{3}{8} \frac{\tau_{\|} \tau_{\perp}^{2}}{\left(\tau_{\|}+\tau_{\perp} / 4\right)\left(\tau_{\|}+\tau_{\perp}\right)}\right] \omega_{Q}^{2} .
\end{aligned}
$$


The extension of the lifetime of the STI compared to the lifetime of Zeeman $D_{z}$ order is therefore

$$
\kappa=\frac{R\left(D_{z}\right)}{R\left(Q_{S T I}^{I P}\right)} .
$$

If the rotational diffusion is very anisotropic with $\tau_{\perp} \ll \tau_{\|}$, one can expect $\kappa>60$. For the case at hand of ethanol-d6, we can simulate our observations with $\tau_{\|} \approx 4 \tau_{\perp}$. The relaxation rate was found to be evaluating the corresponding matrix elements $\left(\mathrm{Q}_{\mathrm{STI}}^{\mathrm{IP}}\left|\Gamma_{\mathrm{Q}}\right| \mathrm{Q}_{\mathrm{STI}}^{\mathrm{IP}}\right)$ and $\left(3^{-1 / 2} / 2 \mathrm{D}_{\mathrm{z}}\left|\Gamma_{\mathrm{Q}}\right| 3^{-1 / 2} / 2 \mathrm{D}_{\mathrm{z}}\right)$. For any operator $\mathrm{X}$, the Liouville bracket is denoted $(\mathrm{XIX})$. The relaxation rates underlying the matrix in Figure 3 were evaluated taking into account the entire Liouville space.

${ }^{1}$ A. Abragam and M. Goldman, Rep. Prog. Phys. 41, 395 (1978).

${ }^{2}$ S. Jannin, A. Bornet, S. Colombo, and G. Bodenhausen, Chem. Phys. Lett. 517, 234 (2011).

${ }^{3}$ Y. S. Feng, T. Theis, X. F. Liang, Q. Wang, P. Zhou, and W. S. Warren, J. Am. Chem. Soc. 135, 9632 (2013).

${ }^{4}$ R. Buratto, A. Bornet, J. Milani, D. Mammoli, B. Vuichoud, N. Salvi,

M. Singh, A. Laguerre, S. Passemard, S. Gerber-Lemaire, S. Jannin, and G. Bodenhausen, ChemMedChem 9, 2509 (2014).

${ }^{5}$ Q. Chappuis, J. Milani, B. Vuichoud, A. Bornet, A. D. Gossert, G. Bodenhausen, and S. Jannin, J. Phys. Chem. Lett. 6, 1674 (2015).

${ }^{6}$ H. Min, G. Sekar, and C. Hilty, ChemMedChem 10, 1559 (2015).

${ }^{7}$ P. R. Jensen, M. Karlsson, M. H. Lerche, and S. Meier, Chem. - Eur. J. 19, 13288 (2013).

${ }^{8}$ E. Miclet, D. Abergel, A. Bornet, J. Milani, S. Jannin, and G. Bodenhausen, J. Phys. Chem. Lett. 5, 3290 (2014).

${ }^{9}$ A. Bornet, X. Ji, D. Mammoli, B. Vuichoud, J. Milani, G. Bodenhausen, and S. Jannin, Chem. - Eur. J. 20, 17113 (2014).

${ }^{10}$ J. N. Dumez, J. Milani, B. Vuichoud, A. Bornet, J. Lalande-Martin, I. Tea, M. Yon, M. Maucourt, C. Deborde, A. Moing, L. Frydman, G. Bodenhausen, S. Jannin, and P. Giraudeau, Analyst 140, 5860 (2015).

${ }^{11}$ M. C. Tayler, I. Marco-Rius, M. I. Kettunen, K. M. Brindle, M. H. Levitt, and G. Pileio, J. Am. Chem. Soc. 134, 7668 (2012).

${ }^{12}$ P. Ahuja, R. Sarkar, S. Jannin, P. R. Vasos, and G. Bodenhausen, Chem. Commun. 46, 8192 (2010).
${ }^{13}$ P. R. Vasos, A. Comment, R. Sarkar, P. Ahuja, S. Jannin, J. P. Ansermet, J. A. Konter, P. Hautle, B. van den Brandt, and G. Bodenhausen, Proc. Natl. Acad. Sci. U. S. A. 106, 18469 (2009).

${ }^{14} \mathrm{P}$. Mieville, S. Jannin, L. Helm, and G. Bodenhausen, J. Am. Chem. Soc. 132, 5006 (2010).

${ }^{15}$ R. Sarkar, A. Comment, P. R. Vasos, S. Jannin, R. Gruetter, G. Bodenhausen, H. Hall, D. Kirik, and V. P. Denisov, J. Am. Chem. Soc. 131, 16014(2009).

${ }^{16}$ L. Lumata, M. E. Merritt, Z. Hashami, S. J. Ratnakar, and Z. Kovacs, Angew. Chem., Int. Ed. 51, 525 (2012).

${ }^{17}$ K. Schmidt-Rohr and H. W. Spiess, Multidimensional Solid-Sate NMR and Polymers (Academic Press, San Diego, CA, 1996).

${ }^{18}$ B. Vuichoud, J. Milani, A. Bornet, R. Melzi, S. Jannin, and G. Bodenhausen, J. Phys. Chem. B 118, 1411 (2014).

${ }^{19}$ T. K. Chen, A. L. Beyerlein, and G. B. Savitsky, J. Chem. Phys. 63, 3176 (1975).

${ }^{20}$ S. Bowen and C. Hilty, Phys. Chem. Chem. Phys. 12, 5766 (2010).

${ }^{21}$ D. Mammoli, B. Vuichoud, A. Bornet, J. Milani, J. N. Dumez, S. Jannin, and G. Bodenhausen, J. Phys. Chem. B 119, 4048 (2015).

${ }^{22}$ Z. W. Zheng, C. L. Mayne, and D. M. Grant, J. Magn. Reson., Ser. A 103, 268 (1993).

${ }^{23}$ L. Müller, A. Kumar, T. Baumann, and R. R. Ernst, Phys. Rev. Lett. 32, 1402 (1974).

${ }^{24}$ P. Bernatowicz, D. Kruk, J. Kowalewski, and L. Werbelow, ChemPhysChem 3, 933 (2002).

${ }^{25}$ J. Milani, B. Vuichoud, A. Bornet, P. Mieville, R. Mottier, S. Jannin, and G. Bodenhausen, Rev. Sci. Instrum. 86, 024101 (2015).

${ }^{26}$ L. G. Werbelow, G. A. Morris, P. Kumar, and J. Kowalewski, J. Magn. Reson. 140, 1 (1999).

${ }^{27}$ J. Kowalewski and L. Maler, Nuclear Spin Relaxation in Liquids: Theory, Experiments and Applications (CRC Press, U.S., 2006).

${ }^{28}$ G. Pileio and M. H. Levitt, J. Magn. Reson. 187, 141 (2007).

${ }^{29}$ R. Poupko, R. L. Vold, and R. R. Vold, J. Magn. Reson. 34, 67 (1979).

${ }^{30}$ M. Carravetta and M. H. Levitt, J. Chem. Phys. 122, 214505 (2005).

${ }^{31}$ P. Bernatowicz and S. Szymański, J. Magn. Reson. 148, 455 (2001).

${ }^{32}$ P. Bernatowicz and S. Szymański, Mol. Phys. 101, 353 (2003).

${ }^{33}$ B. Vuichoud, J. Milani, Q. Chappuis, A. Bornet, G. Bodenhausen, and S. Jannin, J. Magn. Reson. 260, 127 (2015).

${ }^{34}$ J. Nocedal and S. J. Wright, Numerical Optimization (Springer, 2006).

${ }^{35}$ Enterprises S. Scilab, Le logiciel open source gratuit de calcul numérique, 2012.

${ }^{36}$ M. Carravetta, O. G. Johannessen, and M. H. Levitt, Phys. Rev. Lett. 92, 153003 (2004).

${ }^{37}$ F. Delaglio, S. Grzesiek, G. W. Vuister, G. Zhu, J. Pfeifer, and A. Bax, J. Biomol. NMR 6, 277 (1995). 